\title{
EL DESARROLLO DEL FÚTBOL FEMENIL EN MÉXICO: ENTRE LA POLICÍA Y LA POLÍTICA EN LOS PROCESOS DE INCLUSIÓN Y EXCLUSIÓN (1970-2019)
}

\author{
WOMEN'S FOOTBALL DEVELOPMENT IN MEXICO: BETWEEN THE \\ POLICE AND POLITICS WITHIN THE INCLUSION AND EXCLUSIÓN \\ PROCESS (1997-2019)
}

\author{
Daniel Añorve Añorve
}

\begin{abstract}
RESUMEN
Desde el renacimiento del fútbol femenil en México transcurrieron aproximadamente dos décadas para lograr el suficiente grado de institucionalización que llevara a la primera liga femenil profesional. El camino hacia la profesionalización ha estado lleno de ejemplos de inclusiones y exclusiones vis-à-vis el fútbol varonil. El objetivo central de este artículo es aplicar al estudio del proceso de crecimiento e institucionalización del fútbol femenil en México las nociones de policía y política presentes en Jacques Rancière. Especial énfasis merecen dos figuras icónicas Maribel Domínguez como jugadora y Virginia Tovar como árbitro- que en el 2004 desafiaron el status quo prevaleciente dentro del 'juego del hombre'. Se argumenta que la política, como cuenta de los que no toman parte tiene la posibilidad real de cuestionar el orden policial presente en el fútbol mexicano, siempre y cuando logre alterar el sensemaking de los actores dentro de la cancha, de los directivos, de los equipos y desde luego del público. Para evaluar los avances que pueden lograr alterar el sentido común, se propone un análisis de los logros en dos dimensiones: 1) actores a nivel de cancha y 2) los espacios de juego.
\end{abstract}

Palabras clave: Fútbol femenil; Liga profesional; Política; Sensemaking; Género.

\begin{abstract}
Since the rebirth of women's football in Mexico, it took approximately two decades to achieve the necessary degree of institutionalization that ended up with the launch of the first professional women's league. The road to professionalization abounds with examples of inclusion and exclusion vis-à-vis men's football. The goal of this study is to understand the growth and institutionalization of women's football in Mexico through the lenses of Jacques Rancière's notions of police and politics. Special attention is given to two iconic women -Maribel Domínguez as a player and Virginia Tovar as a referee- both women who in 2004 challenged the prevailing status quo within the 'men's game'. It is argued that politics, understood as the accounting of those who do not take part, opens up the possibility of questioning the existing police order in Mexican football, as long as its manages to alter the sensemaking of the on-field actors, the managerial staff, the teams, and the larger football audience. In order to assess the achievements that may end up altering the common sense, two dimensions are analyzed: 1) the on-field actors and 2) the playing venues.
\end{abstract}

Keywords: Women's football, professional leagues, politics, sensemaking, gender.

“Doctor en Ciencias Políticas y Sociales con orientación en Relaciones Internacionales por la Universidad Nacional Autónoma de México. Maestro en Ciencia Política (York University en Canadá). Es profesor de tiempo completo del Departamento de Estudios Políticos y de Gobierno de la Universidad de Guanajuato. Es responsable del Cuerpo Académico “Gobierno, Instituciones y Organizaciones en el Contexto de la Globalización”. Es miembro del Sistema Nacional de Investigadores (SNI), nivel 2. 


\section{INTRODUCCIÓN}

La combinación de varios factores llevan a creer dentro del imaginario popular que el fútbol femenil en general y en México en específico se trata de una 'novedad'. Entre los factores que refuerzan esta idea errónea destacan: La Copa Mundial (oficialmente) femenil existió con poco más de 60 años de retraso respecto al Mundial varonil; la profesionalización del fútbol femenil en efecto es muy reciente (Japón contó con la primera liga semi-profesional femenil en 1989); las abismales diferencias salariales y de cobertura de los mass media han, si no invisibilizado el fútbol femenil, si lo han relegado a un lugar secundario dentro del imaginario popular; finalmente, y de enorme relevancia es lo advertido por Williams (2007), los materiales, archivos, documentos, fotografías e información en general en torno al fútbol femenil están fragmentados y los materiales fuertemente resguardados. En realidad, Williams (2007) y Draxler (2018) argumentan que el fútbol femenil y su popularidad no son una novedad y que de hecho, hace casi un siglo, "para 1920 el fútbol femenil era más popular que el fútbol varonil, atraía multitudinarias audiencias y lograba reunir fortunas para los veteranos de guerra o para los mineros en huelga" (DRAXLER, 2018, p. 14). En realidad, se asegura, la prohibición del fútbol femenil, primero por parte de la Football Association (FA) y luego su replica en otros países como Italia, Francia, Brasil, Alemania, Holanda y desde luego por parte de FIFA, fueron producto del miedo que generaban las posibles consecuencias macro sociales de su popularidad. No fue sino hasta finales de los $60 \mathrm{y}$ principios de los 70 que se levantaron las prohibiciones.

Aunque en México el fútbol femenil no gozaba a inicios del siglo XX de la popularidad documentada en Europa, a inicios de la década de los 70 el fútbol femenil logró una inusitada popularidad debido a los dos podios conseguidos por México en los Mundiales (no reconocidos por la FIFA). En Italia 1970 México obtuvo el tercer lugar. En el Mundial de 1971 disputado en México, la selección mexicana fue subcampeona. Quizá, más que el resultado, lo impresionante sea la asistencia registrada en la gran final disputada en el Estadio Azteca. Aunque no hay un consenso en cuanto a las cifras, se habla de una asistencia que va desde unos 80,000 (Santillán y Gantús, 2010) hasta una asistencia superior a las 100,000 personas (GARIN, 2004 citado en DRAXLER, 2018, p. 19).

Ya sea para el caso europeo o para el caso mexicano, en lugar de referirnos entonces al nacimiento del fútbol femenil, lo que corresponde es hablar de un renacimiento o como sugiere Williams (2007) de un segundo desarrollo del fútbol femenil.

En menos de dos años desde el lanzamiento de la Liga MX Femenil (en adelante, LMXF), no obstante las evidentes brechas existentes respecto a la liga varonil, una serie de éxitos relativos han otorgado notoriedad a la LMXF, incluso internacionalmente. En cuanto a la asistencia promedio a los partidos, se supera con creces la asistencia registrada en las ligas europeas. Al término del torneo Clausura 2019, la asistencia promedio para la temporada regular era de 1,752 asistentes por partido (LIGA MX FEMENIL, N/D). Si se toma en cuenta la asistencia a la liguilla, entonces el promedio asciende a 2,516 (para el Apertura 2018). Para 2017, en Europa se reportaban (UEFA, 2017) sólo seis ligas con más de 1,000 asistentes por partido: Francia $(1,500)$, Portugal $(1,250)$, Inglaterra $(1,128)$, España (1000), Italia (1000) y Kazajstán (1000). En tan solo 18 meses, la LMXF reportó 5 de las 10 asistencias más elevadas de todos los tiempos para el fútbol femenil. El record mundial lo detentó la LMXF con una entrada de 51,211 (MARCA, 2018) hasta marzo de 2019, cuando fue roto en España en un Atlético de Madrid vs. Barcelona.

El artículo consta de cuatro apartados. En el primero, se hace un repaso de la literatura en torno al fútbol femenil en México y de aquella parte de la literatura pertinente para los objetivos de este artículo. Se hace un repaso conceptual de la obra de Rancière, así como de parte de la literatura en torno al sensemaking. El segundo apartado da cuenta del camino hacia la profesionalización del fútbol femenil en México desde la década de los años 90 hasta el lanzamiento de la LMXF. El tercer apartado analiza la evolución de la temprana LMXF (2017-2019) a través de dos dimensiones: los actores en la cancha y las los espacios de juego. Finalmente, se lleva a cabo una discusión en donde se incorpora el análisis 'político' derivado de Rancière para intentar comprender hasta que punto la política ha logrado romper con la lógica y el orden policial del fútbol varonil, y cómo (si es que acaso lo ha hecho), los avances mostrados en el fútbol femenil impactan en el sensemaking, posibilitando, 
potencialmente, desmoronar lo que reste del orden policial existente.

Dos preguntas guían la investigación: ¿Cuáles son las formas concretas que ha tomado el orden policial dentro del fútbol mexicano? ¿Qué evidencias existen de que el proceso político (bajo el entendimiento de Rancière) ha logrado alterar el sensemaking que ha permitido sostener el orden policial?

\section{LITERATURA}

La literatura académica en torno al fútbol femenil en México es casi nula. El único estudio relevante encontrado es el de Santillán y Gantús (2010), estudio de una naturaleza muy diferente al que se plantea aquí. Dicho estudio se enfoca en la forma en que los medios de comunicación representaban a las futbolistas mexicanas en los años 70 , por 1o cual aunque se ofrece un estudio serio en torno a los prejuicios sociales que dificultaron y ralentizaron el segundo desarrollo (Cfr. Williams, 2007) del fútbol femenil en México, no aporta una visión estructural de conjunto de este deporte.

No obstante la ausencia de estudios académicos relevantes, se ha logrado recuperar una cantidad importante de trabajos de difusión menores (Membrilla, 2006; Pereyra, 2006, 2011 y 2018) y de notas periodísticas que permiten brindar luz al período de casi dos décadas transcurrido entre el renacimiento del fútbol femenil en México y el lanzamiento de la LMXF. Entre los artículos, destacan aquellos en la revista Fem de la autoría de Hernández (1998, 1999a, 1999b, 1999c y 2002), así como notas periodísticas (Reforma, 1997; Corzo, 1998; Becerril, 1998, 1999; Miranda, 2000; Juárez, 2002; Huérfano, 2010; El Universal, 2011).

En referencia al fútbol argentino, y sin mencionar en momento alguno a Rancière, un trabajo de Branz (2008), brinda una serie de reflexiones interesantes antes de abordar lo que por medio de la recuperación de Rancière (1996) podría implicar un proyecto político para el fútbol femenil. Lo primero que es preciso reconocer desde la lógica de Branz es lo expuesto por Galindo (2005), en torno a que el deporte es en efecto un espacio social que tiene fisuras y que está sujeto a conflictos de toda índole. Bajo esta premisa, Galindo señala (citado en BRANZ, 2008, p. 47): "El deporte está en la base de la vida social, no es algo secundario ni superfluo". Branz (2008) advierte que más bien la razón por la cual el deporte parece ser ajeno al conflicto es porque casi nunca se conceptualiza como un espacio en donde se dirime el poder y en donde se pueden configurar las relaciones sociales, por lo cual no duda en señalar al deporte: "Como el lugar del poder instituido" (BRANZ, 2008, p. 48). Así, destaca la "decisión política de disputar un espacio cristalizado como masculino" (Branz, 2008: 49). Lo que hace entonces Branz es invitar al debate diacrónico de un problema, aparentemente apolítico. Ciertamente, para fines de este artículo no interesa una de las tres dimensiones propuestas por Branz (2008), la dimensión lúdica, toda vez que el trabajo no aspira a enfrascarse en una discusión sobre consideraciones lingüísticas y/o estéticas en torno al juego. Se recupera por tanto sólo la segunda y tercera dimensión, la productiva y la de la política y la gestión. Lo que sí interesa es la construcción de la identidad y el mito futbolero en Argentina como un dominio exclusivamente varonil y la idea del pibe, excluyendo a las pibas como sugiere Branz (2008, p. 51). Las exclusiones o en el mejor de los casos, la marginalidad de las mujeres en la dimensión productiva del fútbol sí nos compete y sostenemos, tiene que ser parte esencial del proceso de debate político. Es importante entonces analizar las implicaciones de lo presentado por Branz (2008, p. 52) como: "la monstruosidad del negocio mediático en relación al fútbol no admite -salvo excepciones- la incorporación central de las mujeres". Desde luego, Branz advierte que no sólo la brecha salarial es un problema, sino también la realidad de la precariedad laboral, la falta de apoyo de los clubes, lo cual en su conjunto, dificulta la viabilidad del proyecto de profesionalización del fútbol femenil. Para Branz (2008, p. 53) queda claro entonces que "el problema se dirime entre fuerzas sociales desiguales, y en términos políticos". Branz también pone de manifiesto cómo la desigualdad se encubre en un lenguaje pretensamente universal, inclusivo y democrático, usado tanto por las organizaciones internacionales, por FIFA, como por las asociaciones nacionales, al hablar en género masculino dentro de las reglamentaciones (árbitros, jugadores, asistentes, árbitros asistentes). Branz (2008, p. 54) considera que "El espacio perdido (hasta hoy) en la política y la gestión representa la invisibilidad de las mujeres para participar, en forma directa, de las decisiones que tienen que ver con 
sus prácticas deportivas". Sin embargo, dado que el fútbol es presentado como una actividad apolítica y de esparcimiento, hasta el momento, "la cuestión de las mujeres y el fútbol no se admite en el plano del debate y del conflicto" (BRANZ, 2008, p. 54). Invita a entender el fútbol desde lo hegemónico, lo cual genera un determinado sensemaking ( $C f r$. CLARINGBOULD y KNOPPERS, 2008) entendido como proyecto legítimo y cosmovisión oficial, el cual para reproducirse, "debe ser continuamente recreado, renovado y defendido" (BRANZ, 2008, p. 54). Hasta el momento, advierte Branz (2008, p. 54), la hegemonía ha sido más o menos sencilla, toda vez que el fútbol es presentado "como lugar cálido, sin conflictos, y sin la posibilidad de que los haya". Sobre como cambiar el flujo de sentido (BRANZ, 2008, p. 55), sugiere algo que podríamos conectar con el sensemaking, "otorgarle, sin titubeos, el rótulo de problema político. Esto aportaría al proceso de transformación de la idea de que todo lo deportivo no tiene conflictos".

La política, desde la óptica de Rancière (1996, p. 22) nace de la existencia de un sujeto político. Es preciso señalar que este sujeto no es una clase en el sentido marxista; más bien, Rancière considera que dicho sujeto es en realidad el demos. El demos es un sujeto colectivo entendido como "la reunión de hombres de ninguna posición, esos hombres de quienes Aristóteles nos dice "no tienen parte en nada" (RANCIÈRE, 1996, p. 22). La motivación del sujeto político conocido como el demos consiste en la reparación del daño, mismo que no se materializa necesariamente en una acción lasciva o en un sufrimiento físico. Esto es ciertono sólo en México, sino prácticamente en cualquier país, quizá con excepción de lo ocurrido en algunos países escandinavos. El daño va de la mano con la clasificación que experimentan o han experimentado históricamente ciertos grupos de personas dentro de la colectividad, en nuestro caso dentro de una micro-sociedad, llamada fútbol. De esta forma, la política en Rancière intenta tomar en cuenta a aquellas partes que no toman o no han tomado parte y a aquellos cuyo sufrimiento es percibido, por aquellos que en efecto sí cuentan y toman parte en la vida de una comunidad específica, como un simple ruido (Cfr. RANCIÈRE, 1996, p. 37). El sujeto político en el caso de la LMXF podría ser, parafraseando a Rancière, la presente reunión de mujeres de ninguna posición dentro del mundo del fútbol a quienes alguna vez la FIFA, las confederaciones regionales y sus asociaciones nacionales les dijeron que no tenían parte o rol dentro del futbol institucionalizado. Así, la política surge cuando no existe un terreno común y cuando una de las partes se rehúsa a reconocer a sus contrapartes como pares (Cfr. RANCIÈRE, 1996). El momento político se detona cuando una parte excluida de la comunidad decide levantar la voz y busca reparar el agravio percibido.

La política sin embargo, no puede existir con tan sólo tener a las dos partes (la agraviada y que busca la reparación del daño por un lado; por otro, la parte privilegiada que si toma parte y/o que sí es escuchada y tomada en cuenta). En realidad, la política requiere de una disputa, misma que puede ocurrir en la esfera política y posteriormente, por medio de canales legales, lograr el objetivo central, la verificación del logro de la igualdad. Rancière considera que se precisa la fuerza del litigio. A pesar del argumento que, "para 1920 el futbol femenil era más popular que el futbol varonil, atrayendo multitudinariamente a los aficionados y juntando fortunas para los veteranos de Guerra o para los mineros en huelga" (DRAXLER, 2018, p. 14), la Football Association (FA), en Inglaterra, temía las consecuencias que dicha popularidad podría traer aparejadas. La FA llegó a un veredicto en 1921 y falló por medio de reglas contra las mujeres que estuvieron vigente por espacio de 50 años (en 1971 las reglas se declararon nulas). Dichas prohibiciones y limitantes como ya se mencionó se replicaron en varios países. No basta entonces con el levantamiento de la prohibición, sino que se requiere de la verificación de la igualdad, de la verificación de que la parte agraviada, en este caso las futbolistas, podrían ver reparado su agravio, por medio del reconocimiento oficial de los Mundiales femeniles, desde 1991 y con la profesionalización del fútbol en diversos países, a partir de la década de los 90 del siglo XX.

Rancière advierte que la actividad política rara vez se da de forma suave, mucho menos sin conflicto; de hecho, Rancière estudia el frecuente encuentro entre las fuerzas que salvaguardan el status quo, fuerzas que se concretan en la policía y la política, esta última que busca desafiar y romper el status quo: "La política surge cuando el orden de la dominación natural es interrumpido por la institución de una parte que no toma parte" (RANCIÈRE, 1996, p. 25). La 
contraparte de la política es la policía. La policía es la palabra que Rancière (1996, p. 43) usa para referir a la distribución de roles, así como para referir al sistema de legitimaciones existentes dentro de una sociedad. Rancière diferencia a la 'baja' policía, misma que usa uniformes, patrullas y macanas, de la policía entendida como una fuerza intangible, misma que más bien refiere "al orden de lo que es visible y de lo que es decible [...] la fuerza que permite que ciertas palabras pertenezcan al discurso, pero que convierte a otras en ruido" (RANCIÈRE, 1996, pp. 44-45). La policía en el sentido de Rancière, no necesariamente se materializa en una institución tangible y puede estar presente y de hecho salpicar la cultura, en algo similar a lo que sucede con el orden hegemónico en cualquier sociedad.

En realidad, el desorden político es lo que cuestiona, episódicamente, siempre que logre desclasificar el lugar otorgado al demos (en este caso al fútbol femenil) dentro del orden policial. Para el caso de la LMXF, la policía consiste en una mezcla de actores públicos y privados que alimentan el orden policial, sin requerir del Estado para implementar tal orden. Lo importante es comprender cómo fue estructurado el orden policial dentro de esa microsociedad llamada fútbol, la cual no precisaba del calificativo 'varonil', toda vez que el fútbol era por excelencia 'varonil' (Pfister y Pope, 2018). Es entonces, cuando se empieza a hablar de fútbol 'femenil' que se activa políticamente la parte que tradicionalmente no había contado dentro de esa esfera 'masculina' llamada fútbol, más aún cuando se trataba de fútbol en su dimensión productiva, el fútbol profesional. Desde luego, este estudio intentará dar cuenta de cómo por medio de la fuerza del litigio, un demos concreto ha buscado romper con el orden policial, impersonal, estructural, cultural, fuerte y 'naturalmente' enraizado, lo mismo en el fútbol mundial que en el fútbol mexicano.

Adicionalmente, toda vez que uno de los objetivos medulares del presente trabajo es analizar los fenómenos de inclusión y exclusión que ultimadamente puede conducir, ya sea a continuidades o cambios, es importante hacer un breve repaso en torno a la literatura relacionada con el género y el cambio organizacional. Particularmente importante resulta concentrarnos en el sensemaking (CLARINGBOULD Y KNOPPERS, 2008; ALLISON, 2017). Sensemaking hace referencia al proceso que se detona cuando las expectativas originales son violentadas, lo que genera la posibilidad para la activación de significados intersubjetivos, mismos que involucran ciclos de interpretación y acción (MAITLIS Y CHRISTIANSON, 2014). El aspecto más relevante por lo que toca al sensemaking es que abre la posibilidad del cambio al interior de las organizaciones, lo cual incluye la posibilidad de 'deshacer' ('undoing') prejuicios de género, lo cual a su vez implica actuar en cierta forma para desafiar los valores, normas, significados y jerarquías existentes; en breve, se trata de desafiar las conductas y prácticas hegemónicas ( $C f r$. CLARINGBOULD Y KNOPPERS, 2008). Lo anterior, ciertamente, es el equivalente del cuestionamiento, por medio del litigio, de la policía en Rancière. Para estos fines, Claringbould y Knoppers (2008, p. 82) aseguran que el género no existe 'simplemente'; de hecho, existe una 'hechura' del género (gender 'doing') cuando el uso de atributos normativos de género o los estereotipos, dentro de las interacciones sociales, refuerzan las diferencias de género. Al contrario, estas dos autoras reconocen que es posible 'deshacer' el género cuando el status quo es desafiado. El cambio resulta posible cuando las expectativas (ciertamente no objetivas y no compartidas por todos, sino por los actores dominantes, aquellos que constituyen la policía en Rancière) no logran coincidir con la realidad (Allison, 2017). Cunningham (2008) sostiene que el proceso de sensemaking puede respaldar las presiones societales sobre las organizaciones para efectivamente deslegitimar la desigualdad de género.

\section{EL CAMINO HACIA LA PROFESIONALIZACIÓN (1970-2017)}

De acuerdo con Draxler, para agosto de 1971 existían unos 1000 equipos registrados en 26 entidades federativas (México tiene 32 entidades federativas) ante la Federación Mexicana de Futbol Femenil (FMFF). Draxler (2018) y Santillán y Gantús (2010) coinciden en que no fue sino hasta los años 90 del siglo XX que se llevó a cabo el empujón final para institucionalizar el fútbol femenil en México. Es momento de revisar los orígenes distantes del fútbol femenil en México y así ver si existió un primer 'desarrollo' como en Europa (WILLIAMS, 2007) o si lo acontecido con los Mundiales (no-oficiales) 
de 1970-1971 es el primer intento documentado de desarrollo.

Entre los trabajos de divulgación existe una narrativa corta (HERNÁNDEZ, 2002) que permite conocer dos cosas: el fútbol femenil se jugaba en México en 1932, gracias a la compañía alemana, Alegría y Enhart, la cual trajo un equipo para competir contra las escuadras locales en Veracruz. En segundo lugar, después de los logros obtenidos por las selecciones mexicanas en los mundiales de 1970 y 1971 y no obstante el entusiasmo de las mujeres, hombres y patrocinadores, no se dio continuidad al desarrollo del fútbol femenil. De hecho, tomó 20 años para que existiera de nuevo un equipo nacional femenil.

Una nota del periódico Reforma (1997) da cuenta de la inauguración del primer Centro de Capacitación para el futbol femenil mexicano. La nota señalaba: "junto con este centro, que se ubica en las instalaciones de la Confederación Deportiva Mexicana, habrán de funcionar otros en las ciudades de Guadalajara, Monterrey y Cancún" (REFORMA, 1997, p. 4). También se destacaba que el fútbol femenil ya contaba con 52 ligas a lo largo del país. Además destacaba que en julio de 1997 habría de tener lugar el Torneo Nacional de la especialidad en Cancún, Quintana Roo (REFORMA, 1997, p. 4).

En una nota de Hernández (1999a) en torno al Mundial Femenil 1999 celebrado en Estados Unidos, se recuperan algunos datos presentados por Ángel Soto en torno al fútbol femenil en México y su inevitable comparación con el fútbol varonil. Se destacaba que, al término del Mundial de 1998 celebrado en Francia, cada jugador mexicano ganó un bono de 45 mil dólares; en contraste, las becas mensuales de cada jugadora del Tri Femenil era de 3 mil pesos mensuales. Lo anterior se agrega a otras brechas no monetarias: el equipo femenil no contaba con una ginecóloga(o) en el cuerpo médico, los masajes no eran obligatorios tamoco (HERNÁNDEZ, 1999a, p. 47). Entre las cifras proporcionadas por Hernández (1998) respecto a la participación de las mujeres en el fútbol en México destacaba que unas 800 mujeres practicaban el fútbol en alguna de las 60 ligas distribuidas en 22 asociaciones en la República Mexicana, las cuales se encontraban en 19 entidades (Baja California Norte y Sur, Campeche, Chihuahua, Colima, D.F., Estado de México, Guerrero, Guanajuato, Michoacán,
Nayarit, Nuevo León, Quintana Roo, San Luis Potosí, Sinaloa, Tamaulipas, Veracruz, Yucatán, Zacatecas) y dos universidades federales (IPN y UNAM). También aseguraba que otras medidas incluían la decisión de ubicar a mujeres destacadas en el fútbol en alguno de los cuatro Centros de Capacitación de la República para que entrenaran y fueran becarias para su dedicación de tiempo completo. También destaca que ya se pretendía conformar una liga de 12 equipos que pudieran jugar un campeonato en forma, sentando con esto las bases para una futura semiprofesionalización.

Una nota periodística de 1998 del Estado de México presumía el lanzamiento de un torneo de fútbol femenil en el altamente poblado municipio de Naucalpan (CORZO, 1998, p. 21). Dicho torneo se anunció como el primero en su tipo por parte de la administración local. Otra nota que da cuenta de lo que pasaba en el fútbol femenil mexicano, previo al Mundial de 1999 es la de Becerril (1998). La nota se centra en Andrea Rodebaugh y su contratación en lo que aquel momento se observaba, era la única liga profesional de futbol femenil del mundo, la japonesa. Se da cuenta de las ideas que Rodebaugh trajo de vuelta a México y del papel que tuvo en instituciones educativas, como el Tec de Monterrey y sobre todo, al abrir su propia escuela de fútbol, Andrea's Soccer. Ciertamente, la nota brinda lecciones para los actuales dirigentes de la Federación Mexicana de Fútbol (FMF). Aún cuando Japón siempre ha sido un país nacionalista, conocido por los esfuerzos de conservación de su cultura, se destaca que se permite un número limitado de extranjeras en el fútbol femenil japonés, además de que destaca el apoyo de las empresas japonesas en el florecimiento de su liga profesional. Los sueldos que se reportaban en la liga japonesa (2,000-6,000 dólares mensuales), aún cuando las cifras corresponden a mediados de los 90 del siglo XX se puede apreciar eran sustancialmente más altos que los de la LMXF en la actualidad. La nota informa que la escuela de Rodebaugh contaba para 1998 con 355 futbolistas, con clases desde los 4-5 años, además de contar con ligas en las categorías sub-19 y sub-25 (BECERRIL, 1998, p. 76). La nota también es importante para armar el rompecabezas de lo que ocurrió con el fútbol femenil en México después del Mundial no-oficial de 1971. Se alega que surgieron ligas "llaneras", como la "Cabeza de Juárez”, una de las más importantes en el Distrito 
Federal (BECERRIL, 1998, p. 76). Por último, la nota también proporciona datos de la FMF. Se mencionaba que existían unas 80 ligas afiliadas a la FMF, con cerca de 8,000 jugadoras (BECERRIL, 1998, p. 76). Por lo que toca al Mundial Femenil de 1999 en Estados Unidos, las consideraciones de Leonardo Cuellar resultan muy importantes, no sólo para entender los años mozos del fútbol femenil en México, sino que da importantes pistas para comprender la actual LMXF. Cuellar relataba que su proyecto era crear un circuito nacional de fútbol femenil (BECERRIL, 1999). Cuellar señalaba:

Tenemos que ser realistas. Considero que esto apenas es el inicio de lo que puede ser una cultura futbolística femenil en México. El principal objetivo ya se logró: clasificar para el Mundial, crear el interés y la curiosidad para apoyar el programa de desarrollo de esta rama del futbol (citado en BECERRIL, 1999).

Cuellar también advertía que aunque la FMF presumía la existencia de un programa nacional de fútbol femenil llamado "Sydney 2000", él no lo conocía, lo cual no debía ser sorpresa, dada la escasa promoción del fútbol femenil. Cuellar identificaba otras dificultades que enfrentaba para poder montar una selección competitiva para el Mundial de 1999, entre ellas la necesaria comparación con otros países que contaban con ligas profesionales o semi-profesionales. El fútbol femenil en México no contaba con una liga profesional, por lo cual las prioridades de las futbolistas estaban en otro lado. También, Cuellar destaca el valor de los equipos unversitarios en Estados Unidos, pues ante la ausencia de ligas profesionales en el fútbol femenil mundial, o la precariedad de las mismas, el principal semillero o fuente de talento futbolístico estaba en la National Collegiate Athletic Association (NCAA) de Estados Unidos (BECERILL, 1999). No obstante las limitantes estructurales ya señaladas, la nota reconoce que la selección femenil era apoyada con todos los gastos pagados por la FMF para su viaje a San Diego y su concentración en Tijuana. Aunado a lo anterior, se da cuenta de que la FMF gestionó ante la Comisión Nacional del Deporte (CONADE) una beca, ciertamente incipida, de mil pesos mensuales para cada jugadora (Becerill, 1999). Otra cosa que llama la atención, no sólo históricamente, sino que tiene implicaciones clarísimas para el nacimiento de la LMXF es que el grupo contaba con nueve jugadoras con nacionalidad mexicana y estadunidense:

El primer triunfo internacional del futbol femenil mexicano fue posible, en gran medida, por las reformas al artículo 37 de la Constitución Mexicana, gracias a las cuales se integraron a la selecciónfemenil, que consiguió su pase al Mundial de Estados Unidos, nueve jugadoras con doble nacionalidad (BECERRIL, 1999).

Miranda (2000) recupera los testimonios de Leonardo Cuellar. Un avance que destacaba Cuellar a inicios del siglo XXI era el gradual crecimiento de jugadoras nacidas en México versus las nacidas en Estados Unidos. Destaca que para el Mundial de 1999, 11 jugadoras eran nacidas en Estados Unidos y 9 en México. Poco más de un año después, 6 eran nacidas en Estados Unidos y 14 en México. Lo anterior, explciaba Cuellar era producto de una época en la que "no había ninguna clase de desarrollo y se tuvo que recurrir a las mexicanas residentes en Estados Unidos" (citado en MIRANDA, 2000, p. 16). Cuellar destacaba que el escaso talento venía de las preparatorias y las universidades, pero que no había preparación desde la primaria. Cuellar consideraba que la competencia interna elevaría el nivel de las selecciones nacionales. Respecto a la eterna discusión y discriminación entre mexicanas nacidas en Mexico y mexicanas nacidas o desarrolladas en el extranjero, Cuellar recordaba algo muy importante, entonces y en la actualidad:

Hay muchos empresarios que están sentidos de que se les considere mexicanos nada más cuando aportan dinero a México. Pero cuando sus hijas quieren participar como mexicanas en procesos deportivos en México y no sólo estoy hablando del fútbol femenil, se les cree una controversia y no se les considere mexicanas. Mientras las ley las cobije, hay que seguir abriéndoles las puertas (citado en MIRANDA, 2000, p.16).

Es importante destacar que uno de los esfuerzos pioneros para que despegara el fútbol femenil fue el de Andrea Rodebaugh, quien fundó la escuela de fútbol femenil Andrea's Soccer. Para 1999 ya se hablaba de 50 alumnas en la escuela, pionera en el país. Se da cuenta de cómo la escuela llamó podersoamente la atención de la FMF, institución que permitió la afiliación de la escuela y sus equipos, los cuales acabaron por ser reconocidos por la FIFA y 
la Confederación de Norteamérica, Centroamérica y el Caribe de Fútbol (CONCACAF) (CONTENIDO, 1999). La escuela tenía tan pocas alumnas, por lo que su liga sólo constaba de tres equipos. Lo importante sin embargo, es ver la difusión que pudo hacer una mujer que se empoderó fuera del país y que posteriormente ha hecho mucho por desarrollar el fútbol femenil en México.

Una nota de Hernández (1999b) de finales de siglo XX da cuenta del rol marginal del naciente fútbol femenil en México. Recupera las declaraciones de Hugo Enrique Kisse de la FMF en torno a la jerarquía en las consideraciones de la FMF: "primero estaba la selección mayor varonil, después la sub-23, la sub 17, y hasta el final, la selección femenil" ( $C f r$. HERNÁNDEZ, 1999b, p. 47). La nota también recuerda la forma en que las mujeres de la selección femenil que habrían de competir en Juegos Panamericanos en Canadá, fueron desalojadas del Centro de Capacitación para que ahí trabajara la selección varonil, y se les trasladó al Comité Olímpico Mexicano, donde no existían canchas de fútbol; sin embargo, en un logro innegable del fútbol femenil, destacaba: "En breve iniciará el campeonato de la liga de fútbol femenil en México" (HERNÁNDEZ, 1999b, p. 47). Respecto a la cobertura del fútbol en ambas ramas, destacaba que las transmisiones del futbol varonil en los Panamericanos eran en vivo y de forma completa; en contraste, el futbol femenil en la misma competencia, "sólo fue transmitido en forma completa por Tv Azteca cuando se jugó la final, donde México perdió 1 a 0 ante Estados Unidos" (HERNÁNDEZ, 1999b, p. 47).

Para el año 2000 se anunció la puesta en marcha de un Torneo de Copa femenil y de un Torneo de liga femenil (TIRO DE ESQUINA, 2000). Sin embargo, no se trataba de una liga profesional. Lo importante en todo caso, es que dichos torneos estaban ya avalados por la FMF y asupiciados por la Liga Mexicana de Fútbol Femenil. También destaca que la mayoría de los equipos correspondían a equipos que contaban con un equipo varonil en Primera División (UNAM, América, Guadalajara, Atlas, Toluca, Tecos, U. De. G, Necaxa, Cruz Azul, Neza, León, Irapuato, Puebla, Pachuca, Morelia), pero otros pocos no (Oro, Jalisco, Politécnico y Bachilleres) (TIRO DE ESQUINA, 2000).
Para 2002, Juárez (2002) daba cuenta de un Torneo de Invierno de Primera División de futbol femenil, entre los 16 mejores clubes de México. La participación geográfica era muy limitada: escuadras del Estado de México, además del D.F. y Morelos. Este torneo era parte del evento de la Liga Nacional Nacional de Clubes de Futbol Femenil A.C., la cual está integrada por seis zonas y por equipos provenientes de sólo 14 de los 32 estados del país. Mitzi Chavarría, presidenta de la Liga Nacional, aseguraba había 1200 jugadoras registradas. Destaca que se jugaba en categoría libre, con las jugadoras oscilando entre los 13 y los 36 años. También se hablaba de la posibilidad de crear la Primera División "A”, con la intención de ascender a Primera División (JUÁREZ, 2002, p. 15).

Una entrevista de Gustavo Rangel (2003) con Maribel Domínguez revela los avances del fútbol mexicano. Antes que nada, se considera que lo que estaba sucediendo en el deporte mexicano, no sólo en el fútbol era una revolución, en la cual también tomaban parte otras atletas de distintas disciplinas como Nancy Contreras, Ana Guevara y Adriana Fernández (RANGEL, 2003, p. 38). Pese a las limitantes que enfrentaba el fútbol femenil en México, se desprende de la opinión de Domínguez que existían muchos avances, sobre todo en lo que tocaba a la disponibilidad de espacios para entrenar y el acceso a uniformes. Pese a las dificultades, Domínguez consideraba: “...ya no se puede negar el crecimiento del fútbol entre mujeres en México porque es evidente en las canchas la gran participación de las niñas, así que ya no hay marcha atrás, el fútbol femenil ha llegado para quedarse" (citada en RANGEL, 2003, p. 38).

2004 puede ser considerado como el año icónico, un verdadero parteaguas en la evolución del fútbol femenil en México. Dos ejemplos de actores futboleros de primer orden - una jugadora y una árbitro- habrían de cuestionar decididamente el orden policial vigente dentro no sólo del mundo del fútbol mexicano, sino dentro del deporte mexicano y en gran medida dentro de la sociedad mexicana extradeportiva. Por lo anterior, se comentarán con cierto detalle los litigios que habrían de emprender Maribel Domínguez y Virginia Tovar.

Domínguez, mejor conocida en México como 'Marigol', fue en su momento considerada por FIFA como la sexta mejor jugadora del mundo en el año 
2006 (TORRIJOS, 2016). Marigol terminó jugando en el extranjero (Barcelona, Kansas City Mystics, Atlanta Beat, L'Estartit y San Diego Sunwaves) antes de regresar a México como una jugadora veterana, pero no a la LMXF. Marigol cobró popularidad política cuando, como resultado de la inexistencia de una liga profesional femenil, intentó jugar para un equipo de Primera División varonil, los Toros del Atlético Celaya. Aunque el Atlético Celaya estaba dispuesto a contratar a Domínguez para jugar en su equipo de Segunda División, la respuesta de FIFA, por medio de Joseph Blatter fue fulminante: "Si esta señorita quiere jugar entre los hombres, que lo haga, pero no dentro de nuestra institución. No tenemos nada contra el hecho de que mujeres jueguen con hombres, pero no bajo la égida de la FIFA" (LA JORNADA, 2004a). En torno al caso de Marigol, López (s/f: 7) recupera la discusión que se dio dentro del Senado mexicano, cuando las senadoras Lizbeth Rosas del Partido de la Revolución Democrática (PRD) como Lucero Saldaña del Partido Revolucionario Institucional (PRI) pugnaban por la creación de una liga profesional de mujeres, pues la omisión en ese momento conculcaba "los derechos de cualquier mujer, lo que es un signo preocupante de discriminación" (LA JORNADA, 2004b).

Por su parte, cuando se dio la polémica sobre Virginia Tovar, ella ya tenía un largo camino recorrido. Había ya silbado la final del Mundial de 1999 en Estados Unidos, además de que contaba con certificaciones FIFA. Tovar también fue la primera mujer en silbar un partido amistoso de Primera División entre Celaya y Puebla. Tovar además silbó varios partidos en la Primera División A (CONTENIDO, 2001, p. 87). Virginia Tovar fue (y es hasta la fecha) la única mujer en arbitrar un juego varonil de Primera División. Tovar arbitró cuatro partidos entre 2004 y 2008. Los insultos recibidos por Tovar dan cuenta del machismo estructural al cual hacía referencia Grainey (2012). Dicho machismo está presente en jugadores y autoridades. Tovar recuerda que aunque su debut había sido programado para un partido Tigres vs. Irapuato, su debut acabó tomando lugar una semana después en el América vs. Irapuato. Lo relevante es la razón para tal postergamiento. Los directivos de Tigres estaban en contra. Adicionalmente, Tovar recuerda insultos sutiles, pero también algunos insultos francos y abiertos de parte de estrellas como Luis García, Cuauhtémoc Blanco, quien según López (s/f, p. 4) mandó a Tovar 'a lavar los trastes', y Jared Borgetti. En el caso de este ultimo, Tovar da cuenta del incidente: "Apenas estaba tirando el volado para iniciar el partido y me decía '¿para qué la mandan mija si no tiene capacidad?'Y yo le decía 'espérame, todavía no empiezo a arbitrar y ya me estás echando" (citado en PUBLIMETRO, 2017). Sin embargo, en aras de la justicia, es preciso recordar que Pavel Pardo le mostró su apoyo, regalándole un ramo de flores (PUBLIMETRO, 2017). De hecho, para Tovar: "El problema no es el fútbol; el sistema nacional es machista" (citada en LÓPEZ, s/f, p. 5).

Una nota de El Mensajero (2005) presenta una especie de balance implícito de los avances y limitantes que el fútbol femenil presentaba después del primer lustro del siglo XXI. Por un lado, la nota reconocía:

ya dejaron atrás los tiempos en que dormían hacinadas en el antiguo Centro de Capacitación, en los que llegaban a sus partidos oficiales en un microbús o en los que eran consideradas como la última prioridad de la Comisión de Selecciones Nacionales (EL MENSAJERO, 2005, p. 42).

Por otro lado, dejaba entrever que jugadoras con gran talento, que ya podían competir de tú a tú con los grandes equipos mundiales, como lo eran Maribel Domínguez, Paty Pérez y María de Jesús Castillo encontraron acomodo en la Liga Profesional de España. Lo anterior, aunque no lo señala la nota, se debía en gran medida a la inexistencia de una liga profesional en México.

Es posible ver que existe una importante brecha temporal entre las disputas al orden policialpatriarcal en el fútbol y la reivindicación lograda con el lanzamiento de la LMXF en 2017.

En una nota sobre Charlyn Corral de 2006, Membrilla (2006) da cuenta de las oportunidades limitadas que tenían hacia mediados de los años 90 del siglo XX las futbolistas en México. Por un lado, la nota da cuenta de cómo Corral pudo tener sus primeros contactos con los entrenamientos en el Club Pumas, pero que años más tarde fue separada del equipo varonil, por ser mujer (MEMBRILLA, 2006). Como ocurrió con otras futbolistas mexicanas, las limitantes en México hicieron que Corral emigrara a Estados Unidos, en donde jugó en la preparatoria para F.C. Indiana, equipo que tenía muchas de las 
mejores futbolistas del mundo (MEMBRILLA, 2006); sin embargo, la nota también destaca algo muy relevante, lo ocurrido entre su separación del equipo de Pumas y su llegada a Estados Unidos para estudiar la preparatoria. Corral pudo jugar fútbol femenil en Andrea's Soccer, lo cual le permitió exposición en torneos nacionales (MEMBRILLA, 2006).

Las asimetrías con el futbol varonil eran y siguen siendo evidentes, incluso en jugadoras, como Maribel Domínguez, que eran consideradas Top 10 a nivel mundial por parte de FIFA. En una nota de Pereyra (2006), se recuperan datos que dan cuenta de las condiciones del fútbol femenil, incluso de aquellas jugadoras que jugaban en Barcelona. Hacia 2006, Maribel Domínguez reportaba que el Zaragoza le ofrecía de 1800-2000 euros para jugar en ese equipo (PEREYRA, 2006, p. 91). Para el caso de Paty Pérez, mexicana y compañera de equipo de Maribel Domínguez en el Barcelona, se hablaba de que en lo que encontraba equipo viviría de la beca de la CONADE, en aquellos años valuada en unos $\$ 5000$ pesos mensuales (PEREYRA, 2006, p. 91).

Una nota de 2010 (Huérfano, 2010) destaca el papel clave jugado por las instituciones de educación superior en Guadalajara en la promoción y práctica del fútbol entre las mujeres (los casos del Instituto Tecnológico de Estudios Superiores de Occidente (ITESO) y de la Universidad de Guadalajara (UdeG).

En aras de la participación de la selección femenil en el Mundial de 2011 Pereyra (2011) señalaba que pese al creciente reconocimiento del fútbol femenil y de contar con un par de jugadoras con trascendencia internacional como Maribel Domínguez y Charlyn Corral, las diferencias con la selección varonil seguían siendo claras. Aunque a diferencia de la selección femenil participante en el Mundial de 1999 que se entrenaba en un llano del Centro Ceremonial Otomí, "donde driblaban vacas y borregos" (PEREYRA, 2011, p. 74), para 2011, aunque ya se les permitía entrenar en el Centro de Alto Rendimiento (CAR) de la FMF, no se les permitía una concentración completa en dichas instalaciones, teniendo que pernoctar en un hospedaje lejano al CAR. Pereyra (2011, p. 74) destacaba que ya había un presupuesto asignado a las selecciones femeniles, el cual era visto como una inversión, pese a no ser redituable, pero consideraba que éste se daba a "cuentagotas" (PEREYRA, 2011, p. 74). Entre las asimetrías también destaca que las mujeres no tenían acceso a maletas propias para los viajes internacionales (PEREYRA, 2011, p. 74). También destaca como Justino Compeán aclaraba que la liga profesional no podría concretarse en el corto plazo (PEREYRA, 2001, p. 75). Otra de las asimetrías denunciadas es la forma en que cuando Leonardo Cuellar tomó las riendas de todas las selecciones femeniles, se le asignó una oficina de la Tercera División de la FMF (PEREYRA, 2011, p. 75).

Concluimos este recorrido histórico del largo camino hacia la profesionalización recuperando las lecciones más importantes, según Leonardo Cuellar. En 2011, derivado de la medalla de bronce en el fútbol femenil en los Juegos Panamericanos celebrados en Guadalajara, Cuellar consideraba que lo verdaderamente relevante era la aceptación del público de la realidad de la existencia del fútbol femenil y cómo éste finalmente había lograba salir del ostracismo (EL UNIVERSAL, 2011).

Los saldos del orden policial se caracterizan por sus claroscuros: por el lado positivo, se logró romper con el monopolio varonil sobre el fútbol. Las futbolistas comenzaron a recibir apoyos, principalmente en forma de becas, toda vez que el fútbol femenil, aunque tolerado fue clasificado como 'naturalmente' amateur. Las mujeres conquistaron gradualmente el derecho a ocupar instalaciones principales, como el CAR, además de asegurar insumos básicos como los uniformes. No menos importante, es que se instituyeron una serie de ligas, todas amateurs, en diversas entidades federativas. Quizá lo más importante a futuro, y como el semillero que habría de nutrir selecciones nacionales y posteriormente la LMXF, las escuelas de fútbol femenil, como Andrea's Soccer y el apoyo al fútbol femenil dentro de las Instituciones de Educación Superior, habrían de ir desclasificando, desde las bases y desde fuera de la FMF, el orden policial vigente hasta los años 90. Por lo que toca al lado 'oscuro', cualquier discusión seria en torno a la viabilidad de la profesionalización del fútbol femenil estuvo ausente, salvo la discusión en el Senado de 2004, la cual obviamente no prosperó por al menos una década más. Entre los saldos, también se observa que pese al reconocimiento del fútbol femenil como realidad que había llegado 'para quedarse', a las futbolistas se les siguió asignando una baja prioridad, no sólo versus el fútbol profesional varonil, sino incluso versus categorías inferiores 
varoniles. En realidad vemos que una de las mayores libertades que tenían las futbolistas más destacadas era la libertad de 'emigrar' y desarrollarse educativa y deportivamente allende las fronteras mexicanas. El caso Tovar no logró romper de facto el monopolio sobre el arbitraje, por lo cual el fútbol no era el juego del hombre, sólo en cuanto a la producción del juego, sino también en cuanto a los reguladores del mismo. Si las mujeres deseaban ser árbitras, el lugar que el orden policial les asignaría sería como jueces de línea, pero no como árbitros centrales (RÉCORD, 2016).

\section{LA TEMPRANA EVOLUCIÓN DE LA LMXF (2017-2019)}

Al igual que el fútbol profesional (varonil), la LMXF se juga en un formato de dos torneos cortos anuales. El formato de torneos cortos tuvo su inspiración en el fútbol argentino. Los cuatro torneos cortos disputados a la fecha dentro de la LMXF han sido: Apertura 2017(julio-noviembre de 2017); Clausura 2018 (enero-mayo de 2018); Apertura 2018 (julio-diciembre de 2018); finalmente, Clausura 2019 (enero-mayo de 2019). Ciertamente hubo un minitorneo de Copa en el verano de 2017 que precedió al lanzamiento oficial de la LMXF y que se jugó en un solo fin de semana en mayo de 2017. Dicho torneo de Copa no se ha vuelto a repetir y contó con sólo 12 equipos. Los dos primeros torneos de la LMXF (Apertura 2017 y Clausura 2018) contaron con sólo 16 equipos (versus 18 equipos en la liga varonil), pues los dos equipos de la ciudad de Puebla (Puebla y Lobos BUAP) decidieron no participar. Los dos torneos más recientes (Apertura 2018 y Clausura 2019) ya cuentan con el mismo número de equipos (18) que en el caso de la Primera División varonil, siendo de hecho los mismos equipos para ambas ramas. La Liguilla (playoffs) de los dos primeros torneos de Liga constaron sólo de semifinales y finales, a diferencia de lo acontecido con los hombres, cuya Liguilla comenzaba desde los cuartos de final. Durante los dos torneos más recientes, en gran medida se ha homologado el formato, contando con Liguillas, en ambas ramas, con partidos de cuartos de final, semifinales y finales. La única diferencia es que en la rama varonil califican los ocho mejores equipos de la clasificación general, mientras que para la rama femenil califican los mejores cuatro equipos de cada uno de los dos grupos.

\section{LA PRIMERA DIMENSIÓN: LOS ACTORES EN CANCHA}

Los indicadores a estudiar en esta primera dimensión tienen que ver con lo siguiente: la movilidad geográfica de las jugadoras, así como el aporte de la LMXF a las diferentes selecciones nacionales. Por el lado de las entrenadoras, no se limita el análisis al número de entrenadoras, sino que se pone énfasis en el performance de los equipos entrenados por mujeres. Finalmente, toda vez que es muy complicado analizar el performance de las árbitro, se analiza la participación de las mujeres como árbitro o juez central y dentro de las tripletas arbitrales.

Respecto a la movilidad geográfica, probablemente asociada a los éxitos deportivos, destaca que la LMXF, en su primer torneo se caracterizó por ser una liga marcadamente local (local entendido como estatal y no como nacional). De los 16 equipos que disputaron el Apertura 2017, 10 equipos $(62.5 \%)$ tenían una mayoría de sus jugadoras nacidas en la entidad federativa (estado) en donde el equipo jugaba. A nivel LMXF, el porcentaje de jugadoras nacidas en la misma entidad en la que jugaban era de $58.7 \%$. De manera gradual, el número de equipos, el porcentaje de equipos y el porcentaje de jugadoras que son mayoritariamente locales ha disminuido constantemente. Para el Clausura 2019, 6 del los 18 equipos $(33.3 \%)$ cuentan con una mayoría de sus jugadoras nacidas dentro de la entidad. Por lo que toca a la LMXF en conjunto, hoy la mayoría de las jugadoras juega en una entidad diferente a la de su nacimiento, siendo jugadoras 'locales' tan sólo el $43.9 \%$.

Pese a los avances registrados, persisten una serie de brechas. Por ejemplo, las regulaciones de edades. Dichas regulaciones, para el caso varonil, sólo existen en cuanto a jugadores menores de 18 años, pero no existe una regulación para jugadores mayores de edad. El reglamento femenil regula el número de minutos que han de jugar las menores de 17 años, lo cual se entiende desde la lógica del desarrollo del talento juvenil, pero también regula y de hecho restringe severamente la posibilidades de jugar de las jugadoras mayores de 24 años. Si bien es cierto, para 
el Apertura 2017 y el Clausura 2018 la edad superior reglamentada era a partir de los 23 años y no de los 24 como actualmente está dispuesto, es difícil para una jugadora que de facto se convierte en una jugadora dinosaurio a los 24 años, poder aspirar a una carrera futbolística y dedicarse de lleno al fútbol cuando ha sido clasificada, anti-constitucionalmente dicho sea de paso, como una jugadora con utilidad limitada para todo fin práctico. Los agravios se magnifican si se toma en cuenta que una de las disposiciones del reglamento femenil (FMF, 2018) impide (prohíbe) la contratación no sólo de extranjeras, sino también de jugadoras no nacidas en México. México, como país cuya nacionalidad obedece al principio de ius solis, como es común en el continente americano, y como un país que ha sido generoso en todas las modalidades por las que se puede ser mexicano por nacimiento, cuenta con un número importante de mexicanos por nacimiento que no nacieron en territorio mexicano (existe una millonaria diáspora mexicana en Estados Unidos). De acuerdo con el reglamento femenil, sólo las nacidas en territorio mexicano pueden jugar en la LMXF. Lo anterior es un agravio no sólo deportivo sino jurídico y político, pues contraviene el espíritu de la Ley de Nacionalidad de 1998, cuyo fin era aumentar derechos y posibilidades para los mexicanos por nacimiento, nacidos o que crecieron allende las fronteras mexicanas. Por lo que toca a lo estrictamente deportivo, es difícil pensar en una potencia femenil de fútbol cuya liga doméstica prohíba la participación de jugadoras talentosas de otros países. Más aún, esta disposición resulta injustificable, toda vez que las mejores jugadoras mexicanas gozaron de la posibilidad de jugar en las ligas de otros países.

Por lo que corresponde a la aportación de la LMXF a las selecciones nacionales, lo más prudente es contrastarlas con el porcentaje de 'anglos'1, jugadoras que históricamente habían nutrido a las selecciones nacionales (GRAINEY, 2012). La escuadra Sub-17 que participó en el Mundial de 2010 estaba compuesta por un $38.1 \%$ de 'anglos' y un $57.1 \%$ de jugadoras que jugaban en México. La escuadra subcampeona del mundo en Uruguay 2018 tuvo $23.8 \%$ de 'anglos' y $66.7 \%$ de jugadoras que jugaban en México; por lo que toca específicamente a la LMXF, $57.1 \%$ de la

\footnotetext{
${ }^{1}$ Término utilizado por Grainey (2012) para hacer referencia a las jugadoras, ya sea de origen mexicano, nacidas en Estados Unidos; o bien, jugadoras nacidas en México, pero formadas deportivamente en instituciones estadunidenses.
}

plantilla subcampeona jugaba en la LMXF. Para el caso de la selección mexicana sub-20, para el Mundial de 2010, había una situación de paridad: $47.6 \%$ de la plantilla era 'anglo' y $47.6 \%$ jugaba en México. Para el Mundial de 2018, la cifra para las 'anglo' se redujo levemente, quedando en $42.8 \%$, mientras que la participación de las jugadoras que jugaban en México había ascendido al 57.2\%. Destaca que el total de ese porcentaje dentro de la selección mexicana Sub-20 correspondía a jugadoras de la LMXF. Finalmente, por lo que toca a la selección mayor, el 65\% de la plantilla para la Copa Mundial de 1999 estaba compuesta por jugadoras 'anglos'. No se conoce el porcentaje de las que jugaban en México, pero ciertamente no excedía del 35\%. México no clasificó para el Mundial 2019 en Francia (a disputarse este verano); sin embargo, sí se conoce la composición de la escuadra mexicana que participó hace unas semanas en la Copa Chipre: las jugadoras 'anglo' representaban apenas el 11.6\% de la plantilla, mientras que el $69.2 \%$, no sólo jugaban en México, sino que lo hacían en la LMXF.

Respecto a las entrenadoras, a lo largo de cuatro torneos se ha experimentado un descenso en cuanto al número de entrenadoras, pasando de cinco mujeres para el Apertura 2017 a sólo tres para el Clausura 2019. Lo anterior se agrava al considerar el porcentaje, pues para el Apertura 2017 y el Clausura 2018 sólo había 16 equipos en la liga, mientras que el número aumentó a 18 equipos para el Apertura 2018 y el Clausura 2019. Por lo tanto, el porcentaje de entrenadoras ha descendido de $31.3 \%$ de equipos entrenados por mujeres para el Apertura 2017 a sólo $16.7 \%$ para el Clausura 2019. No obstante la disminución en términos absolutos y relativos, el performance de sus equipos no ha palidecido respecto al de los equipos entrenados por hombres dentro de la LMXF. Si tomamos en cuenta el torneo inaugural de la LMXF, el Torneo de Copa 2017, se puede apreciar que en 4 de las 5 liguillas (play-offs), las entrenadoras mujeres han estado presentes. El saldo para las entrenadoras es el siguiente: campeonato y subcampeonato para la Copa 2017, subcampeonato para el Apertura 2017, se quedaron sin Liguilla para el Clausura 2018 y dos entrenadoras estuvieron presentes en la Liguilla del Apertura 2018, llegando una a los cuartos de final y otra a semi-finales. Para el Clausura 2019, dos de las tres entrenadoras lograron calificar a la Liguilla y una de ellas alcanzó las semifinales. En el mismo período 
de tiempo estudiado, de 5 entrenadores cesados, sólo una mujer ha sido cesada, siendo cesados 4 hombres. Si se revisa el porcentaje de puntos posibles obtenidos por los equipos entrenados por hombres y mujeres, tenemos lo siguiente: para la Copa 2017, los equipos entrenados por mujeres obtuvieron el $58.3 \%$ de efectividad por $44.4 \%$ para los hombres. Para el Apertura 2017, la efectividad de las mujeres fue del $40.9 \%$ contra el $46.4 \%$ de los entrenadores hombres. La mayor diferencia se dio para al Clausura 2018, siendo los porcentajes de efectividad de $34.3 \%$ para los hombres y $53.5 \%$ para los hombres. Para el Apertura 2018 los porcentajes de efectividad fueron muy similares, $44.8 \%$ para los entrenadores varones y $43.8 \%$ para las entrenadoras mujeres. Finalmente, para el actual Clausura 2019 los porcentajes de efectividad son de $47.35 \%$ para los varones y $45.13 \%$ para las mujeres. Los éxitos de las entrenadoras no se limitan a la LMXF. A raíz del subcampeonato mundial Sub-17 conseguido en Uruguay 2018 por el equipo entrenado por Mónica Vergara, dos de las tres entrenadoras de los equipos nacionales que compiten internacionalmente son entrenados por mujeres ( $\mathrm{La}$ Sub-17 por Maribel Domínguez y la Sub-20 por Mónica Vergara). Sólo la selección mayor sigue en manos de un entrenador varón. Por otra parte, toda vez que uno de los objetivos de este trabajo es hablar sobre el sensemaking y el proceso para deshacer el género (gender undoing), lo sucedido de forma global en el Mundial Sub-17 de Uruguay 2018 debe ayudar a cambiar el sensemaking alrededor del mundo. Aunque la cantidad de selecciones nacionales entrenadas por mujeres era considerablemente menor que las selecciones entrenadas por varones, 3 de los 4 semifinalistas (incluidos los dos equipos finalistas) eran entrenados por mujeres.

Por lo que corresponde a los árbitros, éste quizá sea el indicador en donde el avance de las mujeres dentro de la cancha haya sido más significativo. Para el Apertura 2017 era sumamente raro hallar una mujer silbando un partido (como árbitro central), pues sólo el $12.50 \%$ de los partidos de temporada regular fueron dirigidos por una mujer. Para el Apertura 2018 el porcentaje alcanzó el $75.7 \%$ de los partidos silbados por una mujer, aunque para el Clausura 2019 disminuyó al 69.4\%. Respecto a las tripletas arbitrales, también se ha visto un aumento en las tripletas arbitrales integradas sólo por mujeres, como para las tripletas arbitrales mixtas. Para el caso de las tripletas arbitrales de sólo mujeres, el porcentaje subió de un 5.4\% para el Apertura 2017 a un $43.2 \%$ para el Apertura 2018, aunque disminuyó a 39.6\% para el Clausura 2019. Para las tripletas mixtas, la cifra subió de 39.3 para el Apertura 2017 a 43.8\% para el Apertura 2018, manteniéndose prácticamente igual para el Clausura 2019 con el 43\%.

\section{LA SEGUNDA DIMENSIÓN: LOS ESPACIOS DE JUEGO}

Además de la FMF y los reglamentos vigentes, es preciso analizar lo que pasa con los equipos y sus esfuerzos para proveer a los equipos femeniles con instalaciones adecuadas para su desempeño profesional-deportivo. Por lo que toca al tipo de instalaciones en las que juegan los equipos de la LMXF, se puede apreciar que para el Apertura 2017 poco más de la mitad (56.3\%) de los partidos se jugaban en instalaciones secundarias (canchas de entrenamiento y/o estadios en los que no jugaban los equipos varoniles). Para el Apertura 2018 el porcentaje había aumentado a 72.2\%, llegando a un $75 \%$ para el Clausura 2019. Para el Apertura 2017, sólo 3 de 16 equipos jugaron la totalidad de sus partidos como locales en el estadio principal (Pachuca, Morelia y León); para el Clausura 2019, 11 de los 18 equipos juegan la totalidad de sus partidos en el estadio principal (Necaxa, Morelia, Toluca, Tigres, Tijuana, Pachuca, Santos, Veracruz, Lobos V BUAP, León y Querétaro). Sin embargo, vale la pena destacar que hay al menos cuatro equipos que o bien siguen jugando en estadios secundarios (Atlas, Cruz Azul y Pumas) o bien han tenido un franco retroceso, pues durante los dos primeros torneos sostuvieron un porcentaje considerable de sus partidos en el estadio principal y en la actualidad han convertido a las canchas de entrenamiento y/o un estadio secundario en su lugar de juego común (el caso del América). Dos equipos representan esta clasificación marginal y/o secundaria asignada a su equipo femenil: por un lado, los Pumas, cuenta con el nada honroso 'reconocimiento' como el único equipo de la LMXF que nunca ha permitido que un partido femenil de la LMXF se lleve a cabo en su estadio (TERRAZAS, 2018). El otro equipo es el América. Después de llevar a cabo un número más o menos equilibrado de juegos 
en el Estadio Azteca y en sus instalaciones de Coapa para el Clausura 2018, para el Apertura 2018 y para el Clausura 2019 envió a jugar a su equipo a Coapa, incluso para la Liguilla del Clausura 2018, torneo en que resultó campeón. Lo anterior es un agravio y una muestra inequívoca de lo más retrograda del orden policial. Sólo fue para la final del Apertura 2018 que el América pudo jugar en el Estadio Azteca. El trato diferenciado para los equipos varoniles y femeniles es claramente ilustrado con la siguiente anécdota. Como parte de los preparativos para el juego de fútbol americano de la NFL a disputarse entre Los Angeles Rams y los Kansas City Chiefs, el 19 de noviembre de 2018, ambos equipos femeniles (Cruz Azul y América) programaron todos sus juegos para el Apertura 2018 en otras instalaciones. Para el caso de Cruz Azul en el Estadio 10 de diciembre en Hidalgo y para el caso del América en las instalaciones de entrenamiento en Coapa. En cambio, los mismos equipos, en su rama varonil, jugaron la mayor parte de sus partidos en el Estadio Azteca; más aún, la superestrella de música pop latina, Shakira, tuvo un par de conciertos en el Estadio Azteca los días 11 y 12 de octubre de 2018. El resultado final fue una cancha en un estado lamentable que llevó a la cancelación del partido por parte de la NFL (BELSON, 2018). En contraste, en lo que parece ser un área de reivindicación para el fútbol femenil, se han hecho significativos avances desde el nacimiento de la LMXF en cuanto a la valoración del juego por parte de los equipos y de los aficionados, lo cual puede ser, tanto producto, como detonador del cambio en el sensemaking. Para el Apertura 2017, la entrada a los estadios era libre (gratuita). Para el Clausura 2019, 11 de los 18 equipos cobran entrada a los partidos, si bien es cierto es necesario hacer tres aclaraciones para matizar esta cifra: la primera es que salvo el Cruz Azul, que ha convertido en su estadio femenil permanente una instalación secundaria, el resto de los equipos cobra entrada a los partidos cuando se juega en el estadio varonil; la segunda es que los precios de las entradas son sumamente bajos, fluctuando entre los \$20 y los \$100 pesos (aproximadamente entre uno y cinco dólares); tercero, 7 de los 11 equipos que cobran admisión regalan la entrada para quienes son abonados del club, es decir que cuentan con el bono anual y/o tarjeta preferencial para el equipo varonil. Sin embargo, es un avance que 4 de los equipos cobren entrada, independientemente de si se es abonado o no. Llama la atención que Tigres, el equipo que jornada tras jornada registra las mejores asistencias en sus partidos como local, es un equipo que sí cobra admisión al estadio, aunque ciertamente permite el ingreso gratuito para los abonados. Con todas las aristas y aclaraciones revisadas, lo que es indiscutible es que la LMXF ha registrado entradas récord y promedios que superan con creces a otras ligas femeniles alrededor del mundo. Finalmente, un hecho significativo es que mientras el Apertura 2017 fue un torneo de entrada gratuita hasta la gran final que sí tuvo un costo, en los más recientes torneos la mayoría de los equipos cobran ingreso a los partidos de Liguilla, incluso para aquéllos aficionados abonados (caso de Chivas en el Apertura 2018).

\section{DISCUSIÓN Y CONCLUSIONES}

Con base en los hallazgos es posible hacer un análisis concreto e informado del balance de fuerzas entre el conservadurismo dentro del orden policial presente en el microcosmos del fútbol mexicano y las fuerzas progresistas, reivindicadas en el momento en que la política da paso al litigio para la reparación del daño.

Por lo que toca al período transcurrido entre el segundo desarrollo del fútbol femenil en México y que buscaba reparar daños pasados y 'contar' a los que no tomaban parte dentro del mundo del fútbol, se pueden apreciar actores importantes que buscaron alterar el status quo, resguardado de forma impersonal por la policía. Estos actores fueron Andrea Rodebaugh, Leonardo Cuellar, Maribel Domínguez, Charlyn Corral, Virginia Tovar por mencionar a los más importantes. Ciertamente, los litigios no se dieron al unísono ni con la misma demanda. Rodebaugh, sin buscar transgredir la esfera del fútbol varonil, decidió abrir una academia ad hoc que normalizaría la práctica del fútbol femenil y que terminaría por nutrir a las diversas selecciones nacionales, con jugadoras como Mariel Gutiérrez, Yamile Franco y Marylin Díaz. Andrea's Soccer representaba la oportunidad de que las futbolistas no tuvieran que hacerse pasar por varones, de que las niñas jugaran con los niños hasta la adolescencia y luego tuvieran que emigrar por la falta de ligas competitivas en México; o bien, de que tuvieran que estar sujetas a los horarios de entrenamiento y actividades de los equipos varoniles. 
Por su parte, Cuellar al igual que Rodebaugh es otro ejemplo de mexicanos que producto de su residencia en otro país pudieron ver que el problema principal en México no era el de una falta de talento, sino el de una cultura machista que limitaba seriamente las posibilidades de participación y desarrollo del fútbol femenil. Ambos ejemplos ilustran cómo a pesar de que no existían restricciones jurídicas para la participación de las niñas y mujeres, en realidad los lugares asignados, aquello que era 'decible' y posible en cuanto al juego femenil, era distinto a lo que era posible y decible para el juego varonil. El orden policial castigaba de forma sutil, con la inexistencia de oportunidades de juego y seguimiento para las niñas y mujeres, y de forma abierta, por medio de restricciones para el desempeño de la actividad profesional o al no permitir que las niñas, pasada cierta edad pudiesen seguir jugando con los niños. Charlyn Corral y Maribel Domínguez son ejemplos claros, no sólo de jugadoras que en algún momento tuvieron que experimentar asumiendo conductas, vestimenta y gesticulaciones que las hicieran pasar por varones, sino también de cómo institucionalmente se separaba inequívocamente al fútbol en sus ramas varonil y femenil, impidiendo la coparticipación. Lo peor de todo, al no existir ligas profesionales en México, la única forma que tenían para 'vivir del fútbol' era emigrar. Finalmente, el caso de Virginia Tovar desnuda abiertamente la clasificación asignada a las mujeres dentro del orden policial. Toda vez que no había impedimento alguno ni constitucional, ni dentro de la Ley Federal del Trabajo para que trabajara como árbitro, y que las consideraciones de seguridad por el presunto diferencial de fuerza física entre hombres y mujeres no podía ser invocado, la forma de sancionar el orden policial se revelaba en su máximo esplendor: no era la FMF, máximo órgano del fútbol mexicano quien sancionaba. Eran los clubes varoniles, los propios jugadores y el público los que a priori, antes de arbitrar, de evaluar su desempeño, ya obstruían su ejercicio profesional.

Lo que puede apreciarse en este primer período (entre el segundo desarrollo del fútbol femenil en México y el lanzamiento de la LMXF) es que la política, en su concepto rancieriano, no contó con un demos como tal, pues no fueron colectivos, menos grupos organizados los que se encargaban de desclasificar, cuestionar y litigar el lugar asignado por el orden policial. Eran voces y demandas individuales. No se halló dentro del material revisado, indicio de un demos activo políticamente. Desde luego, los esfuerzos emprendidos por individuos fueron importantes, quizá decisivos en el lanzamiento de la LMXF; sin embargo, la acción individual, fragmentada y sin un movimiento o presión sostenida postergaron el lanzamiento de la LMXF, coadyuvando a que el orden policial mantuviera una serie de clasificaciones y lugares asignados al fútbol femenil.

¿Qué es entonces lo que ha cambiado con el lanzamiento de la LMXF? Además de la institucionalización evidente del fútbol femenil y la precaria profesionalización del mismo, las oportunidades se abren en múltiples frentes: la posibilidad de jugar en México, la posibilidad de dirigir y de arbitrar para las mujeres. La exposición mediática, aunque marginal vis-à-vis el fútbol varonil, permite acceder a información para el estudio científico de este deporte. Permite dar una creciente visibilidad al fútbol femenil.

Sobre todo, la LMXF puede ayudar a cuestionar, deconstruir, romper y alterar el sensemaking prevaleciente $\mathrm{y} / \mathrm{o}$ hegemónico, el cual hasta hace muy poco parecía estar en línea con la idea 'interiorizada', casi 'naturalizada' de que el fútbol es el juego del hombre. Si el sentido común señalaba que jugadores, entrenadores y árbitros debían de ser varones, los roles que se dejaban para las mujeres dentro del estadio eran los de edecanes, anunciando productos para una clientela predominantemente masculina; porristas, en caso de que algún equipo contara con ellas, y desde luego aficionadas que asistían a los estadios. Lo que se puede ver a raíz del análisis de la primera dimensión, la de los actores en la cancha es que el predominio de árbitros varones ha cedido su lugar al predominio de mujeres como árbitros centrales y a la composición cambiante de las tripletas arbitrales, aunque ciertamente los árbitros tienen una participación significativa en la LMXF que las mujeres simplemente no tienen dentro de la Primera División varonil. En cuanto a los entrenadores, también se ha cuestionado el orden policial. Después de cuatro torneos completos (y de la Copa inaugural), sabemos que no existe un diferencial importante entre el desempeño deportivo de los equipos entrenados por hombres y mujeres. Los logros anteriores se han dado, no obstante la gradual disminución del número total y del porcentaje de 
entrenadoras dentro de la LMXF. Si a los logros de las entrenadoras de la LMXF aunamos que la final del Mundial Sub-17 Uruguay 2018 fue disputada entre dos equipos entrenados por mujeres (España y México) será posible cuestionar argumentos en torno a las capacidades técnicas para dirigir de hombres y mujeres. No obstante estos cambios en los que las mujeres han generado interesantes resultados, el orden policial, en este caso personificado por la FMF ha decidido restringir las edades para las jugadoras de la LMXF y dentro de estas restricciones, reglamentarlas y restringirlas aún más en cuanto al número de minutos que se pueden disputar y/o el número de jugadoras que pueden ser alineadas en un partido; más aún, el orden policial violenta impunemente y sin algún desafío colectivo claro, disposiciones constitucionales y la Ley de Nacionalidad de 1998, al no permitir que jugadoras mexicanas por nacimiento (no nacidas en territorio mexicano) tomen parte dentro de la LMXF.

Por lo que corresponde a la dimensión de los espacios de juego, el orden policial, aunque erosionado después de 4 torneos, sigue vigente, con claras brechas vis-a-vis la Primera División varonil. A pesar de existir una gradual 'mudanza' hacia los estadios principales, hay equipos que son férreos guardianes de los estadios varoniles, asignando a los equipos femeniles como su territorio 'propio' estadios secundarios (Cruz Azul) o canchas de entrenamiento (Pumas, Atlas, América). En el caso del América es difícil de entender la racionalidad de dicha decisión y de hecho, del retroceso experimentado durante el Apertura 2018 y el Clausura 2019. Se trata de un equipo que ha estado presente en todas las semifinales y que es el campeón vigente de la LMXF. Asignar instalaciones secundarias para jugar complica el de por sí difícil camino para obtener patrocinios y ser atractivo para las televisoras. La doble brecha, versus los equipos varoniles en cuanto al acceso a los partidos también es parte del orden policial que no permite ser considerados como 'pares' a los equipos femeniles. Por un lado, 7 de los 18 equipos no cobran el acceso a los partidos de la LMXF (este número aumenta cuando los equipos que sí cobran juegan en instalaciones secundarias y permiten la entrada gratuita). La segunda brecha se da cuando los costos de los boletos para ver a las mujeres son mucho más económicos que aquellos para ver a los hombres. Las anteriores clasificaciones asignadas al fútbol femenil son lascivas.

Con todo, los logros deportivos (el subcampeonato mundial Sub-17), los éxitos nacionales (en la LMXF) e internacionales de las entrenadoras (Mundial Sub-17 en Uruguay 2018), el lucimiento a nivel mundial con entradas récord dentro de la LMXF y la apuesta de ciertos equipos por un desarrollo del fútbol femenil (Tigres, Monterrey y Pachuca) y la gran apuesta de Fox Sports, al adquirir los derechos de transmisión de 6 equipos de la LMXF (González, 2017), dan cuenta que existen actores colectivos (equipos y televisoras) que están conscientes de que el fútbol femenil 'llegó para quedarse' y que el futuro del fútbol es 'femenino' como lo advirtiera Joseph Blatter. Lo que en realidad hace falta, ya no es tanto la desclasificación del lugar asignado. Aunque persisten clasificaciones y/o reclasificaciones de los lugares asignados al fútbol femenil, la combinación de la creciente exposición mediática, los resultados que han roto con las 'expectativas' y la apuesta de algunos actores concretos parecen, si no romper, si erosionar rápidamente el monopolio varonil sobre el fútbol. La pregunta es, ¿cómo acelerar este proceso de erosión y cómo potencializar la política y los litigios para terminar con lo que resta del orden policial? La primera sugerencia es constituir un auténtico demos. A diferencia del segundo desarrollo del fútbol femenil, hoy existen cientos de jugadoras profesionales y miles de jugadoras amateur. Hoy, las entrenadoras y árbitros no tienen que 'mendigar' más un lugar en la cancha. Si algo nos enseña Rodebaugh es que el futbol femenil hubiese sido imposible sin la participación de escuelas y academias, incluidas las instituciones de educación superior. El demos que habrá de liderar tendrá que salir de las canchas, profesionales y amateur, pero tendrá que ser arropado y fortalecido con un movimiento feminista más amplio, que abarque alianzas con las mujeres en el deporte (extra fútbol), con los movimientos feministas al interior de las universidades (extra deportivo), con agencias de mujeres (gubernamental) para ultimadamente presionar a los legisladores (la actual legislatura en México se anuncia como 'la legislatura de la paridad de género) y a los tomadores de decisiones. Actualmente, la Comisión Nacional del Deporte (CONADE) es presidida por primera vez desde su creación en 1988 por una mujer, la ex campeona 
del mundo y ex medallista olímpica, Ana Gabriela Guevara. El deporte y el género tienen cabida dentro de la denominada 4T (Cuarta Transformación). Es momento de que la política rompa con los restos del orden policial y tome cuenta a los 'no contados' históricamente.

\section{REFERENCIAS}

Becerril, SANDRA. No jugamos ni debemos ni podemos ni queremos jugar como hombres, porque no somos hombres: Andrea Rodebaugh. In.: Proceso, 1998, No. 1134, p. 76.

Leonardo Cuellar: Del fracaso en Argentina 78 al Mundial de Estados Unidos 1999. In.: Proceso, 17 de enero. http://link.galegroup.com/apps/doc/A54509565/GPS?u=ugt o01\&sid=GPS\&xid=a7892455 (consultado el 26 de marzo de 2019).

BELSON, KEN. N.F.L. moves game out of Mexico City over field conditions. New York Times, 13 de noviembre. 2018. Disponible en: https://www.nytimes.com/2018/11/13/ sports/nfl-mexico-city.html. Acceso 30 nov. 2018

Branz, Juan. Las mujeres, el fútbol y el deseo de disputa: Cuando lo deportivo debe volverse político. In.: Educación Física y Ciencia, 2008, Vol.10, p. 45-57.

CLARINGBOULD, INGE; KNOPPERS, ANNELIES. Doing and undoing gender in sport governance. In.: Sex Roles, 2008, Vol. 58, No. 1, p. 81-91.

CONTENIDO. Andrea's soccer una señora escuela de futbol, mayo.1999. Disponible en:

http://link.galegroup.com/apps/doc/A54637719/GPS?u=ugt o01\&sid=GPS\&xid=e8a79d96. Acceso 2mar. 2019.

CONTENIDO. Virginia Tovar, arbitra con mucha cancha, febrero. 2001, p. 87.

CORZO, HUGO. Invitan a mujeres a torneo de futbol. Reforma, 1998, 21 de julio.

CUNNINGHAM, GEORGE. Creating and sustaining gender diversity in sport Organizations. In.: Sex Roles, 2008, Vol. 58, No. 1, p. 136-145.

DRAXLER, MIRIAM. El gran mito del futbol femenino. In.: Futbol Total, 2018, Vol. 18, No. 228, p. 12-20.

EL MENSAJERO. ¡Patearan con muchos pantalones hasta China! La Selección mexicana femenil ya trabaja de cara a las eliminatorias del Mundial 2007. 30 de octubre, 2005, p. 42. Disponible en: http://link.galegroup.com/apps/doc/ A138944546/GPS? $\mathrm{u}=$ ugto01\&sid=GPS\& $\mathrm{xid}=\mathrm{b} 33 \mathrm{f} 8279$. Acceso 26 mar. 2019.

EL UNIVERSAL. Futbol femenil por fin salio del ostracismo, dice Leo Cuellar, 28 de octubre, 2011.
FMF. Liga MX Femenil: Reglamento de competencia. Ciudad de México: Federación Mexicana de Fútbol, 2018.

GALINDO, JESÚS. Comunicación y deporte. Un ejercicio de exploración, especulación y análisis, hacia una comunicología posible. In.: Revista Comunicologi@: Indicios y Conjeturas, 2005, No. 4.

GARIN, ERIK. Mundial (Women) 1971. In.: Rec. Sport. Soccer Statistics Foundation, 2004. Disponible en: http:// www.rsssf.com/tablesm/mundo-women71.html. Acceso 18 jun. 2018 .

GONZÁLEZ, SERGIO. Liga MX Femenil, del proyecto a la seriedad. In.: Fox Sports, 11 de octubre, 2017. Disponible en: https://www.foxsports.com.mx/news/326530-la-ligamx-femenil-en-vias-de-la-consolidacion-en-menos-de-unano. Acceso 26 abr. 2019.

HERNÁNDEZ, ELINA. ¿Se acordarán de nosotras en 1999 ? Campeonato mundial de fútbol femenil. In.: Fem, 1998, Vol. 22, No. 183 , p. 48.

. El Mundial Femenil... México presente. In.: Fem, 1999a, Vol. 23, No. 195, p. 47-48.

. (1999b). Igualdad en el deporte principal reto hacia el 2000. In.: Fem, 1999b, Vol. 23., No. 198, p. 47-48.

Presencia dela mujer Mexicana en el deporte. In.: Fem, 1999c, Vol. 23, No. 199, pp. 58-61.

HUÉRFANO, VALERIA. El futbol también es cosa de mujeres. In.: Mural, 28 de junio, 2010.

JUÁREZ, MARISOL. Arranca torneo de futbol femenil. In.: Reforma, 29 de agosto, 2002, p. 15.

LA JORNADA. FIFA rechazó a Maribel Domínguez; no existe el futbol mixto: Blatter, 20 de diciembre, 2004a.

LA JORNADA. Legisladoras piden apoyo para el fútbol femenil, 23 de diciembre, 2004b.

LIGA MX FEMENIL. Asistencia. Disponible en: http:// www.ligafemenil.mx/cancha/asistencia\#asistpromedio. Acceso 28 nov. 2018.

LÓPEZ, GUADALUPE. Las mujeres en el fútbol: una mirada feminista. Heinrich Böll Stiftung: México, Centroamérica y el Caribe, s/f.

MAITLIS, SALLY; CHRISTIANSON, MARLYS. Sensemaking in organizations: talking stock and moving forward. In.: The Academy of Management Annals, 2014, Vol. 8, No. 1, p. 57-125.

MARCA. FIFA: "La Liga MX Femenil debe sentirse orgullosa por lo que ha creado", 5 de mayo, 2018. Disponible en http://www.marca.com/claro-mx/futbol/futbol-femenil/2 018/05/05/5aedd7d3e5fdeaf94b8b45af.html. Acceso 28 jun. 2018. 
MEMBRILLA, RAQUEL. Charlyn Corral. Princesa del área chica. In.: Contenido, 2006, p. 68-70.

MIRANDA, TAY. Mexicanas "muy machas" para jugar. In.: Semana, 22 de diciembre, 2010, p. 16.

PFISTER, GERTRUD; POPE, STACEY. Female football players and fans: intruding into a man's world. London: Palgrave, 2018.

PEREYRA, BEATRIZ. Coraje de mujer. In.: Proceso, 2006, No. 1555 , p. 91.

. Apoyo a cuentagotas. In.: Proceso, 2011, p. 74-76.

Ellas sí pueden vivir del fútbol... pero en España. In.: Proceso, No. 2151, p. 74-76.

PUBLIMETRO. Ex árbitro, Vicky Tovar reveló comentarios machistas de Cuauhtémoc y Jared Borgetti, 8 de marzo, 2017. Disponible en: https://www.publimetro.com.mx/mx/ deportes/2017/03/08/ex-arbitro-vicky-tovar-revelo-ataquesmachistas-cuauhtemoc-blanco-jared-borgetti.html. Acceso 18 jun. 2018.

RANCIÈRE, JACQUES. El desacuerdo. Política y Filosofía. Buenos Aires: Ediciones Nueva Visión, 1996.

RANGEL, GUSTAVO. Pateando la pelota y al machismo. In.: Semana News, 13-19 de abril, 2003, p. 38.

RÉCORD. Tres mujeres debutarán como árbitros asistentes en Liga MX. 14 de julio, 2016. Disponible en: http:// www.record.com.mx/futbol-futbol-nacional-liga-mx/tresmujeres-debutaran-como-arbitros-asistentes-en-liga-mx. Acceso 4 may. 2019.

SANTILLÁN, MARTHA; GANTÚS, FAUSTA. Transgresiones femeninas: fútbol. Una mirada desde la caricatura de la prensa, México 1970-1971. In.: Tzintzun, Revista de Estudios Históricos, 2010, No. 52, p. 141-174.

SPINDOLA, ANA. Tigres femenil con récord de asistencia a nivel mundial. In.: Fútbol Total, diciembre, 2018. Disponible en https://www.futboltotal.com.mx/futbol-mexicano/tigresfemenil-con-record-de-asistencia-a-nivel-mundial/2018/12. Acceso 4 may. 2019.

TERRAZAS, ADRIANA. Un año después, 10 cosas a mejorar en la Liga MX Femenil. In.: ESPN, 8 de mayo, 2018. Disponible en: http://www.espn.com.mx/blogs/ index?nombre $=$ futbol $/$ mexico\&entryID $=4280747$. Acceso 20 feb. 2019.

TIRO DE ESQUINA. Arranca la liga femenil de fut con 20 equipos. 31 de octubre, 2000, p. 8. Disponible en: http://link. galegroup.com/apps/doc/A67151089/GPS?u=ugto01\&sid= GPS\& $x i d=f 26 a 497 f$. Acceso 25 mar. 2019.

TORRIJOS, KARLA. No volveré a involucrarme en la política; lo mío es el futbol: Marigol. La Jornada, 17 de enero, 2016. Disponible en: http://www.jornada.com. mx/2016/01/17/deportes/a09n1dep. Acceso 24 ago. 2018.
UNION OF EUROPEAN FOOTBALL ASSOCIATIONS (UEFA). Women's football across the national associations, 2017.

WILLIAMS, JEAN. A beautiful game: international perspectives on women's football. New York: Berg, 2007. 